\title{
Progress in Solid Oxide Fuel Cell (SOFC) Research
}

\author{
AMIT PANDEY ${ }^{1,2}$ \\ 1.—LG Fuel Cell System, North Canton, OH, USA. 2.-e-mail: dramitpandey@gmail.com
}

Generating renewable electricity is the smartest way to reduce $\mathrm{CO}_{2}$ emissions and is one of the reasons behind the installation of wind/photovoltaic (PV) power plants. However, one of the major drawbacks of renewable energy sources is their power variability. The renewable power plants, therefore, are either required to be over-engineered to take account of this power fluctuation or must be supported by typically fast-response open-cycle gas turbines (going against the low $\mathrm{CO}_{2}$ emission). Ideally, excess renewable energy generated during times of plenty can be stored in hydrogen and batteries for use during periods of insufficient electricity availability. Excess electricity from renewables can be fed into an electrolyzer to produce hydrogen and later used in fuel cells to produce electricity when needed, releasing the stored energy back to the grid. With the steady decline in the cost of PV solar/wind and fuel cells, such integrated energy systems are becoming the reality and provide a sustainable energy solution leading to a net zero-emissions electrical grid. ${ }^{1}$ However, such energy conversion and storage devices face challenges of long life (reliability) ${ }^{2}$ and material degradation (durability). ${ }^{3}$

One such energy conversion system is the solid oxide fuel cell (SOFC). Solid oxide fuel cell systems have been successfully proven to convert chemical energy to electrical and vice versa; i.e., they work as solid oxide electrolysis cell systems.

SOFCs are advanced power generation systems that have demonstrated ${ }^{4}$ the conversion of chemical energy to electrical energy at high temperatures $\left(>700^{\circ} \mathrm{C}\right)$ with high efficiency, fuel flexibility, and significant reduction in greenhouse gases. The demonstration of the viability of long-term stable operation of SOFCs on hydrocarbon fuels (natural gas, methanol, ethanol, and other renewable biofuels) offers additional benefits in terms of infrastructure support ranging from distributed generation to combined heat and power to automotive auxiliary power systems. The high operating temperature of SOFC systems favors the rapid reaction kinetics and steam reforming. A recent book edited by $\mathrm{N}$. Brandon, E. Ruiz-Trejo and P. Boldrin has captured most of the material issues and challenges ${ }^{5}$ in SOFC technology.

The following list summarizes the papers being published under the topic of Advancement in Solid Oxide Fuel Cell Research. To download any of the papers, follow the URL http://link.springer.com/jou rnal/11837/71/1/page/ 1 to the table of contents page for the January 2019 issue (vol. 71, no. 1).

- "Effect of Infiltration of Barium Carbonate Nanoparticles on Electrochemical Performance of $\mathrm{La}_{0.6} \mathrm{Sr}_{0.4} \mathrm{Co}_{0.2} \mathrm{Fe}_{0.8} \mathrm{O}_{3-\delta}$ Cathodes for Protonic Ceramic Fuel Cells" by Jun Gao; Yuqing Meng; Shiwoo Lee; Jianhua Tong; Kyle Brinkman

- "Measurement of Bulk Oxygen Diffusivity in $\left(\mathrm{La}_{0.8} \mathrm{Sr}_{0.2}\right)_{0.95} \mathrm{MnO}_{3 \pm \delta}$ " by Jacob Davis; Uday Pal; Srikanth Gopalan; Karl Ludwig; Soumendra Basu

- "Energetic Ion Irradiation Induced Disordered Nanochannels for Fast Ion Conduction" by Ritesh Sachan; Matthew F. Chisholm; Xin Ou; Yanwen Zhang; William J. Weber

- "Effect of Aluminizing on the High-Temperature Oxidation Behavior of an Alumina-Forming Austenitic Stainless Steel" by Sedigheh Rashidi, Jung Pyung Choi, Jeffry W Stevenson, Amit Pandey, Rajeev Gupta

- "Oxidation Behavior and Chromium Evaporation from $\mathrm{Fe}$ and Ni Base Alloys under SOFC Systems Operation Conditions" by Ashish N Aphale; Boxun Hu; Michael Reisert; Amit Pandey; Prabhakar Singh

- "Low-Cost Getters for High Temperature Electrochemical Systems" by Ashish N Aphale; Boxun $\mathrm{Hu}$; Prabhakar Singh 
The next special topic on SOFCs will be published in November 2019, organized by Soumendra Basu and Amit Pandey. Details are available at jom.tms.org/ EditorialCalendar; search for "November" to see this topic.

\section{REFERENCES}

1. S.J. Davis, N.S. Lewis, M. Shaner, S. Aggarwal, D. Arent, I. Azevedo, and C.T. Clack, Science 360, eaas9793 (2018).

2. N. Mahato, A. Banerjee, A. Gupta, S. Omar, and K. Balani, Prog. Mater Sci. 72, 141-337 (2015).
3. A. Pandey, A. Shyam, Z. Liu, and R. Goettler, J. Power Sources 273, 522-529 (2015).

4. J. Funk, Fuel cells combined with wind, solar are the next clean energy tech. The Plain Dealer. https://www.cleveland.c om/business/index.ssf/2018/10/fuel_cells_combined_with_win d.html. Accessed 4 Oct 2018.

5. N.P. Brandon, E. Ruiz-Trejo, and P. Boldrin, Solid Oxide Fuel Cell Lifetime and Reliability: Critical Challenges in Fuel Cells (2017). ISBN: 9780128097243. 